\title{
POTENCIAL ORGANOGENÉTICO DE TECIDOS CAULINARES E RADICULARES DE CAQUIZEIRO'
}

\author{
LUIZ ANTONIO BIASI ${ }^{2}$; DAYSE CRISTINA DE CARVALHO ${ }^{3}$; \\ GEFERSON DAVI WOLF³; FLÁVIO ZANETTE ${ }^{4}$
}

\begin{abstract}
RESUMO - Com o objetivo de estudar a morfogênese em tecidos caulinares e radiculares de caquizeiro, foram conduzidos diversos experimentos a campo e in vitro. Os experimentos a campo consistiram numa série de trabalhos que envolveram a estaquia de caule e de raiz, a mergulhia e a alporquia do caquizeiro 'Fuyu'. Na estaquia de caule, foram testados o número de folhas, concentrações de AIB, o estiolamento localizado e total. Na estaquia de raiz, foram testados o diâmetro e a posição da estaca. A mergulhia foi testada a campo e em recipientes, sendo combinanda com o estiolamento das brotações, anelamento e aplicação de AIB. Na alporquia, foram testados o anelamento e a aplicação de AIB, sendo os alporques utilizados para outro teste com AIB. Os experimentos in vitro foram conduzidos com plantas juvenis, sendo um trabalho realizado para a indução de organogênese a partir de segmentos radiculares com BAP, TDZ e cinetina $(10 \mu \mathrm{M})$, combinados com AIA $(0,01 \mu \mathrm{M})$, e outro para a indução do enraizamento de brotações pela permanência em meio de cultura com $25 \mathrm{mg} . \mathrm{L}^{-1}$ de AIB e posterior transferência para outro meio de cultura isento de reguladores de crescimento e com carvão ativado. Em todos os experimentos de estaquia de caule, mergulhia e alporquia, não ocorreu a formação de raízes. Apenas na estaquia de raiz houve organogênese, onde as melhores respostas de brotação e enraizamento foram obtidas com as estacas de maior diâmetro e na posição vertical. A organogênese também foi observada em segmentos radiculares in vitro, com uma grande proliferação de calos e gemas induzida pelo uso de TDZ mais AIA. Ao contrário do observado a campo, as brotações caulinares in vitro enraizaram com uma taxa de $66 \%$, com uma emissão média de 4,7 raízes por brotação, mostrando ser uma técnica promissora de clonagem do caquizeiro.
\end{abstract}

Termos para indexação: Diospyros kaki, estaquia, mergulhia, alporquia, estiolamento, reguladores de crescimento.

\section{ORGANOGENETIC POTENTIAL IN STEM AND ROOT TISSUE OF JAPANESE PERSIMMON}

ABSTRACT - With the objective of studying the morfogenesis in stems and root tissue of japanese persimmon, several experiments were conducted in the field and in vitro. The field experiments consisted of a series of works that involved the cutting of the stem and of the root, the layer and the air-layer of the japanese persimmon ' Fuyu'. In the cutting of the stem, the number of leaves, concentrations of IBA, the located and the total etiolation were tested. In the cutting of the root, the diameter and the position of the stake were tested. The layer was tested in the field and in recipients, being combined with the etiolation of the shoots, ring and application of IBA. In the air-layer the ring and the application of IBA were tested, being the air-layers used for another test with IBA. The experiments in vitro were conducted with juvenile plants, being a works accomplished for the organogenesis induction starting from root segments with BAP, TDZ and cinetina $(10 \mu \mathrm{M})$, combined with IAA $(0,01 \mu \mathrm{M})$, and another for the induction of the budding rooting for the permanence culture medium with $25 \mathrm{mg}$.L-1 of IBA and latter transfer for another exempt culture medium of growth regulators and with activated coal. In all the experiments of cutting, layer and air-layer didn't occur the formation of roots. Just in the root cutting there was organogenesis, where the best budding and rooting responses were obtained with the stakes of larger diameter and in the vertical position. The organogenesis was also observed in root segments in vitro, with a great proliferation of callus and buds induced by the use of TDZ plus IAA. Unlike observed in the field, the in vitro budding took root with a rate of $66 \%$, with a medium emission of 4,7 roots per shoot, being a promising technique to the cloning of the japanese persimmon.

Index terms: Diospyros kaki, cuttings, layers, air-layers, etiolation, growth regulators.

\section{INTRODUÇÃO}

O caquizeiro é uma espécie originária da Ásia, sendo que o Japão é o maior produtor mundial de caquis. Atualmente, o cultivo tem crescido muito fora da Ásia, principalmente em países como os Estados Unidos, Israel, Itália, Brasil e Nova Zelândia (Tao \& Sugiura, 1992).

No Brasil, o caquizeiro é cultivado principalmente nas regiões Sudeste e Sul, onde se destacam os Estados de São Paulo, Rio Grande do Sul e Paraná, citados em ordem decrescente de produção. A área cultivada no Brasil atingiu 5.524 ha em 1998, o que correspondeu a uma produção média de 604 milhões de frutos e um valor de produção da ordem de $\mathrm{R} \$ 48.454 .000,00$ (IBGE, 2000).

O caquizeiro é propagado usualmente através da enxertia por garfagem ou borbulhia, sobre porta-enxertos oriundos de

1 (Trabalho 085/2001). Recebido: 11/04/2001. Aceito para publicação: 30/07/2001.

2 Eng. Agr., Dr., Departamento de Fitotecnia e Fitossanitarismo, SCA/UFPR. Caixa Postal 19061. CEP 81531-990, Curitiba-PR. E-mail: labiasi@agrarias.ufpr.br. Bolsista em Produtividade do CNPq.

3 Aluno do Curso de Graduação em Agronomia/UFPR. Bolsista de Iniciação Científica do CNPq.

4 Eng. Agr., Dr., Departamento de Fitotecnia e Fitossanitarismo, SCA/UFPR. 
sementes (Martins \& Pereira, 1989). Os porta-enxertos mais utilizados pertencem à própria espécie Diospyros kaki e às espécies Diospyros virginiana e Diospyros lotus. Os portaenxertos da espécie $D$. kaki são obtidos das próprias variedades cultivadas no Brasil, tais como Luiz-de-Queiroz, Giombo, RamaForte, Chocolate e Trakoukaki (Penteado, 1986).

Esta espécie apresenta grande dificuldade de enraizamento por meio de estacas caulinares (Tao \& Sugiura, 1992). Rubbo (1989) realizou uma série de experimentos com a estaquia lenhosa e herbácea da cultivar Giombo, testando diversas concentrações de AIB em imersão rápida e lenta, em diferentes épocas do ano, não obtendo nenhuma estaca enraizada. Melhores resultados são obtidos com estacas de raízes (Hartmann et al., 1990), conforme verificaram Boliani \& Sampaio (1988), com as cultivares Taubaté e Rama-Forte. Estes autores obtiveram $84 \%$ de regeneração através da estaquia em posição vertical e $60 \%$ com a posição horizontal.

A formação das mudas pela enxertia, sobre porta-enxertos obtidos de sementes, ocasiona uma grande desuniformidade vegetativa nas mudas, que leva à formação de pomares heterogêneos quanto ao porte e vigor das plantas. A solução para este problema passa pelo estabelecimento de uma tecnologia de propagação vegetativa de formação direta das mudas ou de porta-enxertos, o que representará um significativo avanço na cultura do caquizeiro (Martins \& Pereira, 1989).

Pesquisas recentes com o caquizeiro no Brasil demonstraram que as técnicas de cultura de tecidos in vitro apresentam resultados bastante promissores para a clonagem da espécie (Biasi et al., 1999; Salomão et al., 1999; Salomão et al., 2000). A clonagem poderá tornar-se viável após o melhor entendimento e controle da morfogênese do caquizeiro.

Este trabalho foi realizado com o objetivo de estudar o potencial organogenético em caules e raízes do caquizeiro, visando a oferecer subsídios para a definição futura de um protocolo de propagação vegetativa para esta espécie.

\section{MATERIAL E MÉTODOS}

Os experimentos foram realizados com material juvenil, proveniente de sementes retiradas de caquis do tipo variável, e material adulto coletado de plantas da cultivar Fuyu, localizadas no pomar do Centro de Estações Experimentais do Canguiri em Pinhais-PR. A pesquisa foi conduzida na área mencionada, no Laboratório de Micropropagação e na câmara de nebulização do Departamento de Fitotecnia e Fitossanitarismo da UFPR, em Curitiba-PR.

Diversos experimentos foram conduzidos a campo e em casa de vegetação, utilizando as técnicas de estaquia, mergulhia e alporquia, em combinação com o uso de AIB, anelamento e estiolamento.

Nos trabalhos de estaquia de caule, foram testados os seguintes fatores: a)número de folhas $\left(0,1 / 2,1,1 \frac{112}{2}\right.$ e 2 folhas $)$ deixadas na estaca semilenhosa, com $15 \mathrm{~cm}$ de comprimento, utilizando delineamento em blocos ao acaso, com 5 repetições e 10 estacas por parcela, totalizando 250 estacas; b)concentrações de AIB $\left(0 ; 1000 ; 2000\right.$ e $\left.4000 \mathrm{mg} . \mathrm{L}^{-1}\right)$ por imersão rápida (5 segundos) de estacas com 2 folhas, utilizando o delineamento inteiramente casualizado, com 5 repetições e 10 estacas por parcela, totalizando 200 estacas; c)estiolamento localizado, realizando o revestimento do caule ainda verde das brotações novas em crescimento, de plantas a campo, com um pedaço de papel alumínio, com cerca de $5 \mathrm{~cm}$ de largura. Após 30 dias, os ramos estiolados foram cortados logo abaixo da região revestida, e uma mesma quantidade de ramos não estiolados também foi coletada. Antes da estaquia, metade dos ramos estiolados e não estiolados foram tratados por imersão rápida em solução de 10.000 mg. $\mathrm{L}^{-1}$ de AIB. O delineamento foi em blocos ao acaso, com 5 repetições e 10 estacas por parcela, totalizando 200 estacas; d)estiolamento total, realizado com plantas adultas do caquizeiro Fuyu, a campo, na fase de saída de dormência dos ramos, que foram revestidos com sacos plásticos pretos e sacos de papel, para efeito do estiolamento total. Assim que as brotações atingiram cerca de $10 \mathrm{~cm}$ de comprimento, a cobertura foi retirada e as brotações foram coletadas. Antes da estaquia, todas as estacas foram tratadas por imersão rápida em solução de AIB com a concentração de $3000 \mathrm{mg} . \mathrm{L}^{-1}$. O delineamento foi inteiramente casualizado, com 5 repetições e 10 estacas por parcela.

Todos os experimentos de estaquia de caule foram realizados em câmara de nebulização intermitente, utilizando casca de arroz carbonizada como substrato.

$\mathrm{O}$ experimento com estaquia de raiz foi realizado com estacas retiradas de plantas jovens de 2 anos de idade, provenientes de sementes. As raízes foram coletadas no mês de julho, durante o período de dormência das plantas, e cortadas em segmentos de $4 \mathrm{~cm}$ de comprimento. As raízes foram separadas em quatro categorias, de acordo com o seu diâmetro: $2 ; 3 ; 4$ e 5 $\mathrm{mm}$. Também foram testadas duas posições de estaquia: vertical e horizontal. O delineamento experimental foi em blocos ao acaso, com 4 repetições e 10 estacas por parcela. Os tratamentos foram arranjados em esquema fatorial $2 \times 4$, resultantes da combinação dos fatores acima citados. O substrato utilizado foi a casca de arroz carbonizada e a irrigação realizada apenas para manter o substrato úmido. A avaliação foi realizada após 60 dias.

Os experimentos de mergulhia foram conduzidos a campo e em recipientes. O experimento de mergulhia a campo foi realizado com mudas enxertadas da cultivar Fuyu, utilizando a técnica da mergulhia contínua chinesa. As mudas, com um ano de idade, foram plantadas com inclinação de $45^{\circ}$, num sulco aberto com cerca de $15 \mathrm{~cm}$ de profundidade, em julho de 1999 . O plantio foi realizado em linha dentro do sulco, uma planta após a outra, sendo utilizadas 30 mudas. Após a brotação das gemas, que ocorreu no final do inverno, e o seu crescimento, as mudas foram deitadas totalmente dentro do sulco e foi realizada uma amontoa com terra na base das brotações para favorecer o enraizamento. O experimento foi avaliado em junho de 2000, após 11 meses. O experimento de mergulhia em recipientes foi realizado segundo a metodologia empregada por Biasi \& Koller (1993), utilizando também o estiolamento. Inicialmente, os caquizeiros foram semeados em sacos plásticos, em julho de 1997. As plantas obtidas foram enxertadas em julho de 1998 com garfos da cultivar Fuyu. Em janeiro de 1999, as brotações foram podadas, deixandose 5-6 gemas basais e, em seguida, as mudas foram submetidas ao estiolamento total com cobertura de plástico preto. Após o crescimento das brotações (cerca de $10 \mathrm{~cm}$ ), estas receberam os seguintes tratamentos: testemunha, anelamento mais AIB (2000 mg. $\left.\mathrm{L}^{-1}\right)$ e AIB (2000 mg. $\left.\mathrm{L}^{-1}\right)$ aplicado com pasta de lanolina. Cada 
planta foi revestida com uma garrafa plástica preenchida com terra mais casca de arroz carbonizada $(2: 1)$. O delineamento foi em blocos ao acaso, com 5 repetições. $\mathrm{O}$ experimento foi avaliado após 4 meses.

O experimento de alporquia foi instalado em novembro de 1998, em plantas adultas, com os seguintes tratamentos: testemunha, anelamento $(1 \mathrm{~cm})$, AIB e anelamento mais AIB. O delineamento foi em blocos ao acaso, com 4 repetições e 10 alporques por parcela. Os alporques foram preparados na base de ramos em crescimento da estação. O AIB foi aplicado na forma de pasta de lanolina na concentração de $4.000 \mathrm{mg} . \mathrm{L}^{-1}$. O substrato utilizado foi a casca de arroz carbonizada úmida, envolvida por filme de polietilieno transparente e amarradas as extremidades com barbante. Em julho de 1999, o experimento foi avaliado. Com as estacas resultantes, foi instalado outro experimento, tratando todas as estacas com uma solução de AIB a 10.000 mg.L $\mathrm{L}^{-1}$ por imersão rápida ( 5 segundos) da base. As estacas foram separadas de acordo com os tratamentos originais e colocadas em caixas com substrato Plantmax ${ }^{\circledR}$, sendo avaliadas após 90 dias.

Os experimentos conduzidos in vitro foram realizados com plantas juvenis. O primeiro experimento foi realizado com segmentos radiculares $(4 \mathrm{~cm})$ obtidos a partir de embriões germinados in vitro, em meio $\mathrm{MS}^{1} / 2 \mathrm{NO}_{3}$. Neste experimento, foram testadas as citocininas BAP, TDZ e cinetina, na concentração de $10 \mathrm{mM}$, combinadas com AIA (ácido indolacético) $(0,01 \mathrm{mM})$, exceto na testemunha, isenta de reguladores. $\mathrm{O}$ delineamento utilizado foi inteiramente casualizado, com 4 repetições e 3 frascos por parcela. O experimento foi avaliado após 90 dias. As brotações, com pelo menos uma folha expandida, obtidas neste experimento, foram isoladas do explante inicial e utilizadas no segundo experimento, onde foi testado o procedimento de enraizamento de brotações utilizado por BIASI et al. (1993), que consistiu na permanência das brotações em meio de cultura com $25 \mathrm{mg} . \mathrm{L}^{-1}$ de AIB por 10 dias e posterior transferência para um meio com carvão ativado, livre de reguladores de crescimento. A avaliação foi realizada após 60 dias.

\section{RESULTADOS E DISCUSSÃO}

O número de folhas não afetou a capacidade de enraizamento das estacas semilenhosas do caquizeiro 'Fuyu', pois todas as folhas caíram, e as estacas morreram até o final do experimento. A presença de folhas nas estacas proporciona um aumento do enraizamento em muitas espécies, como já demonstrado para o abacateiro (Reuveni \& Raviv, 1981), goiabeira (Pereira et al., 1983), araçazeiro (Nachtigal et al., 1994), videira (Biasi et al., 1997) e laranjeira (Roncatto et al., 1999). As folhas retidas nas estacas continuam o processo fotossintético e as reações de síntese de carboidratos e outras substâncias necessárias para a morfogênese das raízes adventícias (Hartmann et al., 1990). O conteúdo de carboidratos dos ramos foi positivamente correlacionado com a habilidade de enraizamento em plantas de difícil e fácil enraizamento de Phoenix dactylifera (Reuveni \& Adato, 1974). Entretanto, em plantas de difícil enraizamento, como goiabeira serrana (Fachinello et al., 1992), guabirobeira (Scutti, 1999), abacateiro (Barrientos-Priego et al., 1986) e framboeseira cv. Admiral (Howard et al., 1987), apenas a presença de folhas não é suficiente para estimular a organogênese em tecidos já diferenciados, como ocorreu para o caquizeiro neste trabalho.

A utilização de AIB nas concentrações de 0 a 4000mg.L${ }^{1}$ não apresentou efeito sobre a emissão de raízes nas estacas semilenhosas do caquizeiro 'Fuyu'. Todas as estacas morreram até a data da avaliação, sem apresentar brotação ou formação de calo na base. Este resultado também foi observado em estacas lenhosas e herbáceas do caquizeiro ‘Giombo', que morreram sem apresentar resposta à aplicação de AIB (Rubbo, 1989). As auxinas são conhecidas pelo seu efeito indutor de raízes em estacas e freqüentemente consideradas como limitantes do enraizamento, mas possuem pequeno ou nenhum efeito em espécies lenhosas de difícil enraizamento (Wilson, 1994).

O estiolamento localizado não afetou a formação de raízes ou formação de calo, sendo que todas as estacas estavam mortas na avaliação final. O estiolamento é uma técnica que apresenta bons resultados no aumento da capacidade de enraizamento em espécies de difícil enraizamento (Biasi \& Koller, 1993; Maynard \& Bassuk, 1988), mas não foi verificado com o caquizeiro. Mesmo combinando o estiolamento com a aplicação de $10.000 \mathrm{mg} . \mathrm{L}^{-1} \mathrm{de}$ AIB não houve resposta. Da mesma forma que no experimento anterior, o estiolamento total não estimulou a formação de raízes nas estacas, que morreram até o final do experimento. $\mathrm{O}$ estiolamento total apresenta, de forma geral, para as espécies de difícil enraizamento, resultados melhores do que o estiolamento localizado (Maynard \& Bassuk, 1986). Entretanto, no caquizeiro, nem desta forma houve enraizamento, o que demonstra um impedimento muito grande para a rizogênese, que deve estar associado a fatores internos fisiológicos ainda não elucidados.

As estacas de raiz apresentaram resposta organogenética, ao contrário do observado com os experimentos de estaquia de caule. Para as variáveis porcentagem de estacas brotadas, comprimento das brotações e número de folhas das brotações, não houve interação significativa entre os fatores estudados, apenas de forma independente. A posição vertical apresentouse superior em todas as variáveis citadas, com mais de $50 \%$ de estacas brotadas e com brotos maiores (Tabela 1). A polaridade no caquizeiro é bastante marcada, pois as brotações apenas ocorreram na porção proximal das estacas, concordando com Simão (1998). Quanto ao diâmetro das estacas, apenas houve diferença significativa para a variável comprimento das brotações, onde as estacas com maior diâmetro apresentaram maior comprimento. Entretanto, para as demais variáveis (porcentagem de estacas brotadas e número de folhas), apesar de não ocorrer significância estatística, houve uma tendência de superioridade nos diâmetros maiores (Tabela 1).

Para a variável porcentagem de estacas enraizadas, houve interação significativa. As estacas com os maiores diâmetros foram superiores às de $2 \mathrm{~mm}$ na posição vertical. A posição vertical foi superior à horizontal em todos os diâmetros, exceto com as menores de $2 \mathrm{~mm}$, onde o enraizamento foi muito baixo (Tabela 2). Estes resultados concordam com as observações de Boliani \& Sampaio (1988), que obtiveram maior enraizamento com estacas de caquizeiro na posição vertical.

$\mathrm{Na}$ mergulhia a campo e em recipientes, não houve enraizamento. A utilização de estiolamento em mudas com posterior mergulhia apresenta bons resultados para a clonagem de espécies de difícil enraizamento, como o abacateiro (Biasi, 1995), mas não apresentou nenhuma resposta para o caquizeiro. 
TABELA 1 - Efeito do diâmetro e da posição da estaca de raiz na brotação, comprimento e número de folhas dos brotos de caquizeiro.

\begin{tabular}{lccc}
\hline POSIÇÃO & ESTACAS BROTADAS & COMPRIMENTO D A S & NÚ MERO DE \\
& $(\%)^{1}$ & BROTAÇÕES $(\mathrm{cm})$ & FOLHAS/ESTACA \\
\hline Vertical & $51,5 \mathrm{a}^{2}$ & $2,5 \mathrm{a}$ & $1,6 \mathrm{a}$ \\
Horizontal & $21,2 \mathrm{~b}$ & $0,6 \mathrm{~b}$ & $0,2 \mathrm{~b}$ \\
\hline D IÂMETRO & & $2,4 \mathrm{a}$ & $1,3 \mathrm{a}$ \\
\hline $5 \mathrm{~mm}$ & $47,5 \mathrm{a}$ & $2,5 \mathrm{a}$ & $1,3 \mathrm{a}$ \\
$4 \mathrm{~mm}$ & $37,8 \mathrm{a}$ & $1,1 \mathrm{ab}$ & $0,6 \mathrm{a}$ \\
$3 \mathrm{~mm}$ & $28,4 \mathrm{a}$ & $0,4 \mathrm{~b}$ & $0,2 \mathrm{a}$ \\
$2 \mathrm{~mm}$ & $27,1 \mathrm{a}$ & 24,6 & 23,6 \\
\hline C.V.(\%) & 22,1 & &
\end{tabular}

1 Dados transformados em arc-sen $(\mathrm{X} / 100)^{1 / 2}$ para efeito de análise estatística.

2 Médias seguidas pela mesma letra na coluna não diferem significativamente, pelo teste de Tukey, a $5 \%$ de probabilidade.

TABELA 2 - Efeito do diâmetro e da posição da estaca de raiz na porcentagem de estacas enraizadas.

\begin{tabular}{|c|c|c|}
\hline \multirow[t]{2}{*}{ D IÂ M E T R O } & \multicolumn{2}{|c|}{ P O S IÇ Ã O } \\
\hline & Vertic a l & Horizontal \\
\hline $5 \mathrm{~m} \mathrm{~m}$ & 23,1 a A $^{1,2}$ & 3,7 a B \\
\hline $3 \mathrm{~m} \mathrm{~m}$ & 20,6 a $A$ & 1,6 a B \\
\hline $2 \mathrm{~m} \mathrm{~m}$ & $1,6 \mathrm{bA}$ & 1,6 a $\mathrm{A}$ \\
\hline
\end{tabular}

1 Dados transformados em arc-sen $(\mathrm{X} / 100)^{1 / 2}$ para análise.

2 Médias seguidas pela mesma letra, maiúscula na linha e minúscula na coluna, não diferem significativamente, pelo teste de Tukey, a $5 \%$ de probabilidade.

TABELA 3 - Resposta morfogenética de explantes radiculares de caquizeiro em meio de cultura $\mathrm{MS}^{1} / 2 \mathrm{NO}_{3}$ com diferentes combinações de reguladores de crescimento.

\begin{tabular}{cccc}
\hline Tratamentos & $\begin{array}{c}\text { Exp lantes com } \\
\text { calos e gemas }(\%)\end{array}$ & $\begin{array}{c}\text { Explantes com brotos e } \\
\text { folhas exp andidas }(\%)\end{array}$ & $\begin{array}{c}\text { Exp lantes com raízes } \\
\text { novas }(\%)\end{array}$ \\
\hline Testemunha & 0 & 25 & 8 \\
Cinetina $(10 \mu \mathrm{M})+$ A IA $(0,01 \mu \mathrm{M})$ & 0 & 0 & 0 \\
BAP $(10 \mu \mathrm{M})+$ A IA $(0,01 \mu \mathrm{M})$ & 0 & 8 & 0 \\
TDZ $(10 \mu \mathrm{M})+$ A IA $(0,01 \mu \mathrm{M})$ & 89 & 0 & 0
\end{tabular}

Não houve enraizamento nos alporques realizados a campo. Apenas ocorreu a formação de calos nos tratamentos com anelamento. Apesar de o processo de alporquia ser considerado mais eficiente do que a estaquia, como em hibiscus (Lucchesi, 1993), com o caquizeiro, isto não ocorreu. Os ramos coletados da alporquia, que foram utilizados na seqüência para o experimento de estaquia, também não enraizaram, e no momento da avaliação já se encontravam todos mortos.

Ao contrário do observado a campo, no cultivo in vitro, foi obtida uma taxa de $66 \%$ de enraizamento das brotações, que apresentaram, em média, 4,7 raízes por brotação. Este protocolo, já utilizado em abacateiro (Biasi et al., 1993), mostrou-se eficiente para o enraizamento de brotações juvenis, necessitando ser testado para explantes de tecidos adultos. Os tecidos juvenis respondem melhor aos estímulos do que os tecidos adultos, sendo que a redução da capacidade de enraizamento é uma das conseqüências do envelhecimento ontogenético (Assis \& Teixeira, 1998). Isto foi verificado por Salomão et al. (2000) para o caquizeiro 'Cereja'. O enraizamento in vitro de brotações de caquizeiro já foi obtido em diversas cultivares (Cooper \& Cohen, 1984; Sarathchandra \& Burch, 1991; Tao \& Sugiura, 1992).

No experimento de organogênese com segmentos de raízes, ficou novamente evidente que os tecidos radiculares possuem uma competência maior do que os caulinares para expressar o seu potencial morfogenético. Segundo Kerbauy (1999), as respostas específicas de diferentes partes da planta são determinadas pela competência das células-alvo, de tal forma que os hormônios, por si sós, não controlam o padrão de diferenciação celular. Foi observada a formação de uma massa de calo com grande quantidade de gemas nos explantes tratados com a combinação de TDZ e AIA, não respondendo à presença de cinetina. A conjugação BAP e AIA promoveu a formação de 
algumas brotações e, mesmo na testemunha, houve a brotação e enraizamento de alguns explantes (Tabela 3 ). A zeatina, na concentração de $10 \mu \mathrm{M}$, combinada com $\operatorname{AIA}(0,01 \mu \mathrm{M})$, mostrouse superior na indução de brotações em segmentos radiculares do caquizeiro 'Jiro' in vitro (Tetsumura \& Yukinaga, 1996).

\section{CONCLUSÕES}

1. Os tecidos radiculares do caquizeiro possuem maior competência morfogenética do que os caulinares, respondendo de forma mais intensa aos estímulos para a formação adventícia de novos órgãos.

2. Os métodos de propagação vegetativa via mergulhia, alporquia e estaquia caulinar são ineficientes para o caquizeiro 'Fuyu'.

3. O cultivo de tecidos in vitro permite um maior controle e expressão do potencial organogenético, sendo uma técnica promissora para a clonagem do caquizeiro.

\section{REFERÊNCIAS BIBLIOGRÁFICAS}

ASSIS, T.F.; TEIXEIRA, S.L. Enraizamento de plantas lenhosas. In: TORRES, A.C.; CALDAS, L.S.; BUSO, J.A. Cultura de tecidos e transformação genética de plantas. Brasília: EMBRAPA/SPI, 1998. v. 1, p. 261-296.

BARRIENTOS-PRIEGO, A.; BORYS, M.W.; BARRIENTOSPÉREZ, F. Rooting of avocado cuttings (Persea americana Mill.) cvs. Fuerte and Colin V-33. California Avocado Society Yearbook, v. 70, p. 157-163, 1986.

BIASI, L.A. Propagação do abacateiro. Pesquisa Agropecuária Catarinense, v. 8, n. 3, p. 29-31, 1995.

BIASI, L.A. Emprego do estiolamento na propagação de plantas. Ciência Rural, Santa Maria, v. 26, n. 2, p. 309-314, 1996.

BIASI, L.A.; CARVALHO, D.C.; ANDRADE, A.; ZANETTE, F. Estabelecimento in vitro do caquizeiro 'Fuyu' por meio de ápices meristemáticos. Revista Brasileira de Fruticultura, Cruz das Almas, v. 21, n. 3, p. 279-283, 1999.

BIASI, L.A.; KOLLER, O.C. Propagação clonal do abacateiro cv. Ouro Verde através da mergulhia de ramos estiolados. Revista Brasileira de Fruticultura, Cruz das Almas, v. 15, n. 3, p. 95-101, 1993.

BIASI, L.A.; KOLLER, O.C.; KAMPF, A.N. Micropropagação do abacateiro 'Ouro Verde' a partir de segmentos nodais. Pesquisa Agropecuária Brasileira, Brasília, v. 29, n. 7, p. 10511058, 1994.

BIASI, L.A.; POMMER, C.V.; PINO, P.A.G.S. Propragação de porta-enxertos de videira mediante estaquia semilenhosa. Bragantia, Campinas, v. 56, n. 2, p. 367-376, 1997.

BOLIANI, A.C.; SAMPAIO, V.R. Regeneração de espécies frutíferas através de estaquia de raízes de "seedlings" novos e de plantas adultas. In: CONGRESSO BRASILEIRO DE FRUTICULTURA, 9., 1987. Campinas, Anais... v. 2, p. 793-796, 1988.

COOPER, P.A.; COHEN, D. Micropropagation of japanese persimmon (Diospyros kaki). Combined Proceedings International Plant Propagators' Society, v. 34, p. 118-124, 1984.

FACHINELLO, J.C.; MIELKE, M.S.; NACHTIGAL, J.C. Propagação vegetativa da goiabeira serrana. Revista Brasileira de Fruticultura, Cruz das Almas, v. 14, n. 3, p. 233-236, 1992.

HARTMANN, H.T.; KESTER, D.E.; DAVIES JUNIOR, F.T. Plant propagation: principles and practices. 5 ed. Englewood Cliffs: Prentice Hall, 1990. 647p.

HOWARD, B.H.; TAL, E.; MITRA, S.K. Red raspberry propagation from leafy summer cuttings. Journal of Horticultural Science, Ashford, v. 62, n. 4, p. 485-492, 1987.

IBGE. www.sidra.ibge.gov.br. Consulta 23/11/2000.

LUCCHESI, A.A. Propagação de plantas através da alporquia. Piracicaba: ESALQ/CENA, 1993. 8p. (Informativo Técnico, 13).

KERBAUY, G.B. Competência e determinação celular em cultura de células e tecidos de plantas. In: TORRES, A.C.; CALDAS, L.S.; BUSO, J.A. Cultura de tecidos e transformação genética de plantas. Brasília: EMBRAPA/SPI, 1999. v. 2, p. 519-531.

MARTINS, F.P.; PEREIRA, F.M. Cultura do caquizeiro. Jaboticabal: FUNEP, 1989.71p.

MAYNARD, B.K.; BASSUK, N.L. Etiolation as a tool for rooting cuttings of difficult-to-root woody plants. Proceedings International Plant Propagators' Society, v. 36, p. 488-495, 1986.

MAYNARD, B.K.; BASSUK, N.L. Etiolation and banding effects on adventitious root formation. In: DAVIES, T.D.; HAISSING, B.E.; SANKHLA, N. (Eds.). Adventitious root formation in cuttings. Portland: Dioscorides Press, p. 29-46, v. 2, 1988.

NACHTIGAL, J.C.; HOFFMANN, A.; KLUGE, R.A.; FACHINELLO, J.C.; MAZZINI, A.R.A. Enraizamento de estacas semilenhosas de araçazeiro (Psidium cattleyanum Sabine) com o uso do ácido indolbutírico. Revista Brasileira de Fruticultura, Cruz das Almas, v. 16, n.1, p. 229-235, 1994.

PENTEADO, S. Fruticultura de clima temperado em São Paulo. Campinas: Fundação Cargill, 1986. 173p.

PEREIRA, F.M.; OIOLI, A.A.P.; BANZATTO, D.A. Enraizamento de diferentes tipos de estacas enfolhadas de goibeira (Psidium guayava L.) em câmara de nebulização. Científica, Jaboticabal, v. 11, n. 2, p. 239-244, 1983.

REUVENI, O.; ADATO, I. Endogenous carbohydrates, root promoters, and root inhibitors in easy- and difficult-to-root data palm (Phoenix dactylifera L.) offshoots. Journal of the American 
Society for Horticultural Science, Alexandria, v. 99, n. 4, p. 361363, 1974.

REUVENI, O.; RAVIV, M. Importance of leaf retention to rooting of avocado cuttings. Journal of the American Society for Horticultural Science, Alexandria, v. 106, n. 2, p. 127-130, 1981.

RONCATTO, G.; GONÇALVES, E.D.; DUTRA, L.F.; KERSTEN, E. Influência do sombreamento das plantas e do ácido indolbutírico no enraizamento de estacas de laranjeira (Citrus sinensis (L.) Osbeck) cv. Valência. Revista Científica Rural, v. 4, n. 2, p. 60-65, 1999.

RUBBO, M.S. Estudo do enraizamento de estacas de caquizeiro (Diospyros kaki L.). 1989. 90f. Dissertação (Mestrado em Fitotecnia)-ESALQ/USP, Piracicaba, 1989.

SALOMÃO, L.C.C.; VIECCELLI, J.C.; SIQUEIRA, D.L.; OTONI, W.C. Micropropagação de caquizeiro 'Cereja' por meio de gemas apicais e laterais de plantas juvenis e adultas. Revista Brasileira de Fruticultura, Cruz das Almas, v. 22, n. 1, p. 66-71, 2000.

SALOMÃO, L.C.C.; VIECCELLI, J.C.; SIQUEIRA, D.L.; OTONI, W.C.; SISTE, C.E. Micropropagação de caquizeiro (Diospyros kaki L.) por meio de gemas laterais e apicais de plantas adultas. Revista Ceres, Viçoso, v. 46, n. 265, p. 267-277, 1999.
SARATHCHANDRA, S.U.; BURCH, G. Micropropagation fo japanese persimmon (Diospyros kaki Thun.) cv. 'Hiratanenashi'. New Zealand Journal of Crop and Horticultural Science, v. 19, p. 113-120, 1991.

SCUTTI, M.B. Propagação vegetativa da guabirobeira (Campomanesia xanthocarpa Berg.) in vitro e por estaquia. 1999. 95p. Dissertação (Mestrado em Produção Vegetal)Universidade Federal do Paraná, Curitiba, 1999.

SIMÃO, S. Tratado de Fruticultura. Piracicaba: FEALQ, 1998. 760p.

TAO, R.; SUGIURA, A. Micropropagation of japanese persimmon (Diospyros kaki L.). In: BAJAJ, Y.P.S. Biotechnology in agriculture and forestry. High-Tech and Micropropagation II. Berlin: Springer-Verlag. 1992. V. 18, p. 423-440.

TETSUMURA, T.; YUKINAGA, H. High-frequency shoot regeneration from roots of japanese persimmon. HortScience, Alexandria, v. 31, n. 3, p. 463-464, 1996.

WILSON, P.J. The concept of a limiting rooting morphogen in woody stem cuttings. Journal of Horticultural Science, Calcutta, v. 69, n. 4, p. 591-600, 1994. 